\title{
SOBRE O LUGAR DA FILOSOFIA NO ENSINO MÉDIO E NA EDUCAÇÃO CIENTÍFICA
}

\author{
On Philosophy's place in High School and Scientific Education
}

\author{
Nadja Azevedo de Jesus ${ }^{1}$ \\ Deivide Garcia da Silva Oliveira ${ }^{2}$ \\ Lília Ferreira Souza Queiroz ${ }^{3}$ \\ Thaís Soares Silva ${ }^{4}$
}

\begin{abstract}
Resumo: Este artigo tem o propósito de analisar historicamente o lugar da filosofia no Ensino Médio em geral e, em especial, a sua relação com a educação científica, através de uma metodologia teórica, por meio de textos, artigos, decretos e leis, que envolvem o contexto histórico em questão. Primeiramente, abordam-se, no panorama internacional, as mudanças gerais curriculares em ciências ocorridas nos Estados Unidos e o processo de reaproximação entre a filosofia, a história e a educação em ciências, mas apenas na medida de sua utilidade para compreender tal problema no contexto brasileiro. Diante disso, enfatizam-se os aspectos políticos e educacionais que conduziram as idas e vindas (chamaremos de 'ondas') da filosofia no Ensino Médio no Brasil, desde a sua institucionalização a partir da Lei orgânica Capanema (1942), passando pela ditadura militar de 1964, que modificou a estrutura educacional da época, influenciando o panorama atual frente às recentes reformas do Ensino Médio registradas na Lei 9.394/96. Ao mesmo tempo, chama-se atenção para os constantes ataques à filosofia, mostrando que a supressão direta ou indireta dela prejudica o ensino de ciências de modo específico. Nessa perspectiva histórica, extrai-se uma lição das consequências de se dispensar a filosofia da Educação Básica e científica no cenário nacional e se observa como tal dispensa ao longo das décadas do século XX se refletiu até nossos dias no século XXI.
\end{abstract}

Palavras-chave: Filosofia. Currículo. Educação Científica. Ensino Médio brasileiro.

Abstract: This article aims to analyze historically the place of philosophy in high school, in general, and its relationship with science education, in particular, through a theoretical

\footnotetext{
1 Graduanda em Licenciatura em Biologia pela Universidade Federal do Recôncavo da Bahia (UFRB). Integrante o Grupo de Estudos em Filosofia, Ciência e Educação Científica (G-Efficientia). Orcid: https://orcid.org/0000-0002-5979-2837. E-mail: nadja_lua@hotmail.com

2 Professor Adjunto da Universidade Federal do Recôncavo da Bahia (UFRB). Coordenador do Grupo de Estudos em Filosofia, Ciência e Educação Científica (G-Efficientia). Orcid: https://orcid.org/0000-0002-5004194. E-mail: deividegso@ufrb.com

3 Doutoranda em Ensino, Filosofia e História das Ciências pela Universidade Federal da Bahia (UFBA). Integrante o Grupo de Estudos em Filosofia, Ciência e Educação Científica (G-Efficientia). Orcid: https://orcid.org/0000-0002-7129-4881. E-mail: 1souzaqueiroz@gmail.com

4 Doutoranda em Ensino, Filosofia e História das Ciências pela Universidade Federal da Bahia (UFBA). Integrante o Grupo de Estudos em Filosofia, Ciência e Educação Científica (G-Efficientia). Orcid: https://orcid.org/0000-0002-2902-3594 E-mail: ssoares.thais@gmail.com
} 
methodology, through texts, articles, decrees and laws that involve the historical context in question. Firstly, in the international scenario, we approach the general curricular changes in sciences that occurred in the United States and the process of rapprochement between Philosophy, History and science education, but only to the extent that it is useful to understand this problem in the Brazilian context. Therefore, we will emphasize the political and educational aspects that led the comings and goings (we will call waves) of philosophy in high school in Brazil, since its institutionalization from the Capanema Organic Law (1942), through the military dictatorship of 1964, that modified the educational structure of the time, influencing the current panorama towards the recent reforms of high school, registered in the law 9.394/96. At the same time, we will draw attention to the constant attacks on Philosophy, showing that its direct or indirect suppression harms science teaching in a specific way. In this historical perspective, we will learn a lesson about the consequences of dispensing the philosophy of basic and scientific education, on the national scene, and as such dispenses throughout the decades of the 20th century has been reflected up to our days in the 20th century XXI.

Keywords: Philosophy. Curriculum. Scientific Education. Brazilian high school.

\section{Introdução}

A educação brasileira atualmente está caminhando para uma direção que, historicamente, já se mostrou prejudicial tanto para a educação geral (filosófica) quanto para a educação científica, apesar de se anunciar noutro caminho. Embora haja amplo reconhecimento da filosofia como indispensável para o desenvolvimento da reflexão e do criticismo dos estudantes (FOURÉZ, 1995; PRAIA; CACHAPUZ; GIL-PÉREZ, 2002; RODRIGO, 2009; SAVIANI, 2008) ao longo da história da educação brasileira, a referida disciplina teve momentos em que foi dispensada e/ou secundarizada até chegar ao ponto em que atualmente se encontra, diluída na recente reforma curricular do Ensino Médio. A consequência disso é que a disciplina, na prática, perde seu lugar consolidado na grade, e, assim, toda a necessária carga de habilidades e competências que a filosofia traria para uma boa formação geral e científica também se perde. Assim, a secundarização da filosofia causa prejuízos não apenas para a filosofia, mas também para a formação científica, visto que a alfabetização científica ${ }^{5}$, enquanto parte fundamental para a boa educação científica, requer um diálogo com a filosofia.

Nesse contexto, o problema do lugar da filosofia também se estende para a educação científica, a qual por anos se dissociou da história e filosofia das ciências e, desde a década de 90, se reaproximou sistematicamente. Esse distanciamento se manteve por muitos anos tanto no Brasil quanto em outros países, a exemplo dos Estados Unidos, onde passou por momentos de aproximações, distanciamentos e reaproximações com a filosofia. Sobre isso, é importante notar, como neste caso, que na prática da pesquisa e do ensino há uma relação de mútua necessidade entre filosofia e história que se reforça quando se trata de ciências.

Quando ocorridos, esses distanciamentos implicaram a suposta dispensabilidade da filosofia enquanto área de conhecimento fundamental para a formação do estudante de ciências. Esses momentos ocorridos na educação americana desconheceram limites e se projetaram nos currículos educacionais de ciências brasileiros (KRASILCHIK, 2000).

Para além disso, no Brasil, seus próprios contextos históricos e políticos adicionaram combustível para essa separação. Um exemplo concreto foi a ditadura militar, a qual

\footnotetext{
${ }^{5} \mathrm{O}$ que chamamos de alfabetização científica se constitui por essa capacidade de leitura, interpretação crítica e condição de interferência, logo vai para além da mera aprendizagem de conceitos e técnicas científicas.
} 
modificou a estrutura educacional da época com a vinculação da educação pública aos interesses e às necessidades do mercado e o favorecimento da privatização do ensino, entre outras medidas. Nesse período, o modelo educacional tinha como objetivo principal formar indivíduos para o mercado de trabalho pela chamada pedagogia tecnicista - que estava associada com a ideia das competências na Teoria do Capital Humano ${ }^{6}$, formalizada por Theodore Schultz (1961) -, que reificação do ser humano, refletindo um projeto de nação e sociedade que instrumentalizou a educação em detrimento de uma formação mais humana e profunda, substanciada pela filosofia (SAVIANI, 2008). O que seria melhor para tal projeto do que um cientista sem amarras filosóficas expostas?

Por tais motivos, o presente trabalho objetiva analisar historicamente o lugar da filosofia na educação científica do Ensino Médio, considerando o processo de reaproximação entre a filosofia, a história e a educação em ciências e seu reflexo para a educação brasileira. Também iremos expor como a filosofia, no que chamaremos de 'sete ondas', foi sistematicamente alvo de ataques. Esses ataques, naturalmente, se refletem também na qualidade de ensino de outras áreas, como as ciências naturais. Como afirmamos, tal discussão é importante tanto para produzir uma educação geral mais crítica quanto uma formação científica mais crítica e ciente de suas intricadas relações com outras áreas, produzindo sujeitos capazes de meditar sobre a natureza da ciência e de suas teorias, sempre em inexorável relação com a filosofia (FOURÉZ, 2003).

\section{Aproximações, distanciamentos e reaproximações: breve histórico da filosofia no ensino de ciências nos Estados Unidos}

Na década de 1930, segundo Hurd (1998, p. 408), "havia uma defesa para que os currículos de ciências não ficassem limitados apenas ao conteúdo específico, mas que levasse em consideração dimensões socioculturais das ciências", o que, por si só, indicava uma necessidade de uma educação científica substanciada também pelas humanidades, mas isso iria mudar nos próximos anos.

De acordo com Matthews (1989), em seu artigo "A Role for History and Philosophy in Science Teaching", no final dos anos de 1950 e início de 1960, nos Estados Unidos, verificou-se uma grande mudança no que se refere ao ensino de ciências, isto é, a retirada das questões filosóficas dos currículos de ciências como um reflexo do que se entendia por necessidade de um ensino, a saber, que objetivasse criar pequenos cientistas, ou seja, "direcionada a um grupo restrito de indivíduos a fim de que pudessem tornar-se os cientistas e engenheiros do futuro" (MURI, 2017, p. 28). Essa situação se estabeleceu a partir das necessidades criadas com a corrida espacial e bélica, levando os estadunidenses a mudarem seus programas de ciências, visando assim a garantir a hegemonia estadunidense sobre o mundo geopolítico e econômico. Esse projeto incentivou a busca por novos talentos para a carreira científica na escola secundária de base tecnicista (KRASILCHIK, 2000).

A comunidade universitária, com o estímulo do governo, realizou uma série de modificações nos currículos de ciências. Com uma abordagem de especialização e tecnicismo,

\footnotetext{
${ }^{6}$ Fomentada nos Estados Unidos, Theodore Schultz (1961) escreve sobre a Teoria do Capital Humano (TCH), argumentando que o crescimento econômico e a superioridade produtiva dos países tecnicamente avançados estão entrelaçados com as habilidades e os conhecimentos do ser humano, os quais passam a ser tornar commodities, frutos da indústria moderna. A educação, sob esse viés, faria parte da esfera econômica. A escola é uma ferramenta do sistema econômico utilizada para formar sujeitos voltados para o mercado de trabalho, associada a um interesse político e/ou econômico e disfarçada por uma ideia de uma falsa escolha por parte do sujeito. Nesse sentido, em 1964, no Brasil, aconteceu o golpe da ditadura militar, e a TCH teve uma grande influência nas políticas de educação brasileira, contribuindo para a pedagogia tecnicista.
} 
os novos currículos enfatizavam conteúdos específicos das disciplinas científicas, a exemplo da Física (Physical Science Study Commitee - PSSC), Biologia (Biological Science Curriculum Study - BSCS), Química (Chemical Bond Approach - CBA) e Matemática (Science Mathematics Study Group - SMSG). Devido a suas siglas, esses currículos ficaram conhecidos como sopa alfabética (KRASILCHIK, 2000). Mas, para alçar seus objetivos, se acreditou que seria necessário retirar ou secundarizar nos currículos as disciplinas de/voltadas para filosofia e história das ciências, pois, como diz Matthews, se pensou que, para aprender ciências, não se requereria aprender sobre sua história, filosofia ou contexto social, sendo esses aspectos considerados 'menores' (1989, p. 3, tradução nossa, grifo nosso).

Todas essas mudanças ocorridas no final dos anos 50 e início dos anos 60 se mantiveram até o início dos anos 80 , sendo consideradas necessárias para a aproximação dos estudantes com a ciência e para garantir estudantes nas carreiras científicas. Porém, o efeito da separação da ciência e da filosofia foi justamente o contrário. A estratégia de especialização e tecnicismo extremamente conteudista conduziu a um ensino de ciências descontextualizado, e, ao manter a filosofia na periferia da formação científica, eram ignoradas questões sobre a natureza e o objetivo das ciências (MATTHEWS, 1989).

Diante disso, a partir de meados da década de 80, cresceu o número de autores que evidenciaram a necessidade de uma aproximação da educação em ciências com a história e a filosofia, pois a separação descaracterizava o fazer científico enquanto uma atividade composta e permeada por várias áreas. Apesar disso, a separação permaneceu por muitos anos, assim prejudicando o ensino de ciências, além de reduzir o espaço de importância da filosofia (MATTHEWS, 1995). Afinal, não há melhor recurso científico para um governo bélico do que um cientista puramente tecnicista (MARCUSE, 1969).

Na década de 90, ficou especialmente mais clara a necessidade de uma análise da atividade científica no âmbito educacional (MATTHEWS, 1995) e, portanto, da história e da filosofia para uma adequada compreensão das ciências. A partir de então, houve uma "reaproximação" - termo usado por Matthews (1995, p. 4) - entre essas áreas. Sobre esse caso, disseram Aduriz-Bravo e Ariza:

\begin{abstract}
Nos últimos vinte anos surge no campo das didáticas uma extensa e ativa área de investigação, inovação, docência e extensão, conhecida pelo acrónimo inglês "HPS" (History and philosophy of science for science teaching) como área de investigação, inovação, docência e extensão, hoje consolidada como um campo específico de trabalho (2012, p. 81, tradução nossa, grifo dos autores).
\end{abstract}

Assim, o percurso de reaproximação entre a História e a Filosofia das Ciências e o ensino de ciências encontrou grande apoio, e um dos elementos que corroboraram essa reaproximação foi a preocupação internacional em reduzir a identificada crise no ensino de ciências.

A preocupação referida, também encontrada noutros autores como Freire Jr. (2002), advém concretamente do surgimento de uma crise no ensino de ciências que foi originada, entre outras coisas, pela ilusão de autossuficiência da ciência, o que resultou numa abordagem tecnicista e pouco reflexiva, produzindo a evasão de estudantes das aulas de ciências nos Estados Unidos, onde disciplinas como filosofia não eram obrigatórias (FREIRE JR., 2002; MATTHEWS, 1989, 1995). Tais impactos ocorreram também noutros países, como a Bélgica, com a diminuição da procura por carreiras científicas nas universidades (FOURÉZ, 2003).

No bojo desse desinteresse, os estudantes, apesar de compreenderem a importância da atividade científica e de admirarem os cientistas, tiveram frustradas suas expectativas de que as ciências e o ensino de ciências pudessem lhes ajudar a compreender e viver melhor em seu 
mundo, uma vez que a educação em ciências foi esvaziada de debates filosóficos que, não raramente, atentam para os problemas que as ciências se propõem a tratar.

\subsection{A relação entre a alfabetização científica e a filosofia para a educação em ciências}

Tal esvaziamento trouxe para a educação em ciências, entre outras coisas, o analfabetismo científico, que também é fruto da referida crise e dos longos períodos em que História, Filosofia e subáreas como História e Filosofia das Ciências (HFC) mantiveram-se afastadas do ensino de ciências. A busca pela compreensão da alfabetização científica está envolta numa série de controvérsias das quais não poderemos tratar aqui ${ }^{7}$, mas que, entretanto, em geral tem o seu conceito de alfabetização ligado uma formação para além da memorização de teorias, conceitos, leitura de signos (SASSERON; CARVALHO, 2011). A partir disso, ao nos referirmos à ideia de alfabetização (embora focados em ciências), estaremos pensando na noção freiriana de alfabetização. Para o autor, o estudante é alfabetizado quando significa e ressignifica o mundo em que vive e vai para além do saber ler e escrever meras palavras, conceitos, teorias (1987, p. 20; 35). Para Freire,

[...] a alfabetização é mais que o simples domínio psicológico e mecânico de técnicas de escrever e de ler. É o domínio destas técnicas em termos conscientes. [...] Implica numa autoformação de que possa resultar uma postura interferente do homem sobre seu contexto (1980, p. 111).

Assim, a alfabetização, que nós estendemos aqui para a noção de alfabetização científica, supostamente requereria do estudante mais que apenas o domínio de conceitos, escrita e leitura de teorias científicas. Na visão tradicional do conceito, tais elementos seriam suficientes. Porém, Paulo Freire nos permite abrir outra porta para o conceito. Alfabetizar seria, pois, um ato de articulação dos conceitos, das teorias, do mundo, dos sujeitos e de suas realidades, num eterno ciclo que em algum ponto implica autonomia do sujeito na sua formação. Daí que noutro livro Freire repete que "alfabetizar é conscientizar" (1987, p. 14), isto é, nas dimensões desse processo complexo, educar e alfabetizar em ciências significam tornar o agente consciente da natureza das ciências. Assim, no prefácio de Pedagogia do Oprimido, o professor Ernani Fiori diz: "Talvez seja este o sentido mais exato da alfabetização: aprender a escrever a sua vida como autor e como testemunha de sua história, isto é, biografar-se, existenciar-se, historicizar-se" (1987, p. 12). Nessa relação articulada, o estudante significa e ressignifica as informações à sua disposição, reflete, produz existência singular e pessoal à ciência ao testemunhar e debater suas relações com ela - a ciência como uma das atividades epistêmicas mais influentes no mundo atual -, aprendendo com isso a agir conscientemente na realidade. Sobre isso, Freire diz:

\footnotetext{
De alguma maneira, porém, podemos ir mais longe e dizer que a leitura da palavra não é apenas precedida pela leitura do mundo, mas, por uma certa forma de "escrevê-lo" ou de "reescrevê-lo", quer dizer, de transformá-lo através de nossa prática consciente. Este movimento dinâmico é um dos aspectos centrais, para mim, do processo de alfabetização $(2005$, p. 20).
}

\footnotetext{
7 Um exemplo é o debate sobre a tradução correta do termo em inglês literacy, que, segundo o Thesaurus americano e britânico, se traduz como habilidade para ler e escrever, resultando em dois termos no português: Letramento e Alfabetização. Não entraremos nos pormenores do debate porque, para nossos propósitos, as diferenças de tradução são sanadas com a noção freiriana de definição do que seja alfabetização. É claro que Paulo Freire não estava pensando em educação em ciências ao definir alfabetização, mas não vemos motivo para não estendê-la para as ciências. Para mais sobre isso, ver: SASSERON, L. H.; CARVALHO A. P. C. Alfabetização Científica: uma revisão bibliográfica. Investigações em Ensino de Ciências, v. 16, n. 1, p. 59-77, 2011.
} 
Essa noção de alfabetização freiriana, embora não pensada para o contexto científico em si, cabe muito bem para ele, e, sempre que utilizarmos o conceito adiante, será dentro dessa definição. Ainda mais, ele reforça a relação necessária entre tal forma de alfabetização e a filosofia das ciências e a história das ciências. O motivo, de novo, é a flexibilidade e o desenvolvimento crítico que as ciências, associadas à filosofia, proporcionarão para o entendimento dos estudantes acerca das teorias e dos debates científicos.

Esse entendimento envolve por si mesmo a compreensão das relações e dos elementos envolvidos na construção do conhecimento científico e, não menos importante, das consequências que disso resultam e para quem elas resultam (FREIRE, 1980, 1987, 2005). Logo, no combate ao analfabetismo científico, há aquilo que Matthews chama de abordagem contextualista, isto é, "uma educação em ciências, onde estas sejam ensinadas em seus diversos contextos: ético, social, histórico, filosófico e tecnológico" (1989, p. 166, tradução nossa).

O argumento descrito por Matthews é o de que "os alunos devem aprender não somente o conteúdo das ciências atuais mas também algo acerca da "natureza da ciência", (1995, p. 166) e que, assim, educação em ciências é mais adequada quando ela é em e sobre as ciências, sendo que, para tanto, qualquer ciência seria, por si só, incapaz de fornecer uma educação crítica. Aliás, como bem disse Feyerabend, a educação em ciências deveria evitar reducionismos e demarcações muito precisos e surreais entre filosofia, história e ciências em prol do "interesse dessas três disciplinas" (1993, p. 34, tradução nossa).

Infelizmente, não foi esse o caminho entre as áreas científicas no cenário internacional tomado pelo Brasil; por esse motivo, passaremos agora a analisar o lugar da filosofia em suas diversas influências e sua história dentro do Brasil, resultando no que chamamos de 'ondas' contra a filosofia.

\section{Breve histórico do ensino de filosofia no Brasil e suas implicações para o ensino de ciências}

No Brasil, o ensino de filosofia não é algo recente, estando presente na escola secundária desde o período Colonial. Entretanto, durante esse período se manteve instável e com funções pouco definidas (RODRIGO, 2009). Vale ressaltar que essa posição de instabilidade da filosofia não aconteceu somente no Brasil, como argumenta o professor português Manuel Maria Carrilho no trecho a seguir:

É que, se há disciplina cujo estatuto tenha variado no conjunto dos currículos escolares, surgindo ora pletórico e dominante em relação às outras disciplinas, ora encurralado e em quase desaparecimento, essa disciplina é a filosofia. E poucas disciplinas terão também suscitado tantas discussões e debates sobre o seu nível de inserção, o seu tempo de leccionação escolar, e, sobretudo, os seus conteúdos e objectivos (1987, p. 25 apud RODRIGO, 2009, p. 8).

Diante do exposto, podemos notar que momentos de instabilidade permeiam a disciplina Filosofia não somente no Brasil, mas também em Portugal. As influências portuguesas conduziram o ensino de filosofia no Brasil Colônia, uma vez que a função da disciplina se limitava à doutrinação e à manutenção das estruturas de poder. E, apesar das inúmeras legislações posteriores no campo da educação, nenhuma delas aproximou a disciplina da realidade brasileira, algo que se estendeu até o início do século XX. Por isso, damos a esse período o nome de ' 1 a onda' contra a filosofia (Colonial-Imperial). Bem posteriormente, no governo Vargas, a disciplina recebeu algum espaço com as Leis Capanema (1942) e Linhares (1946), descritas nas figuras 1 e 2, mais adiante. 
Os esquemas demonstram duas leis orgânicas muito importantes: a Lei ${ }^{\circ} 4.244$, de 9 de abril de 1942 (Figura 1), que se refere ao ensino secundário; e a Lei ${ }^{\circ} 8.530$, de 2 de janeiro de 1946 (Figura 2), que se refere ao chamado ensino normal, destinado à formação de docentes e administradores escolares.

A lei orgânica de 1942 dividia o ensino secundário em dois ciclos: o $1^{\circ}$ ciclo compreende um só curso, o ginasial, com duração de 4 anos, ou seja, preparatório para o segundo ciclo, o colegial, que apresenta dois cursos paralelos, o clássico e o científico, com duração de 3 anos cada.

Figura 1 - Lei orgânica Capanema (1942) - Getúlio Vargas (2 e $3^{\mathrm{a}}$ Repúblicas)

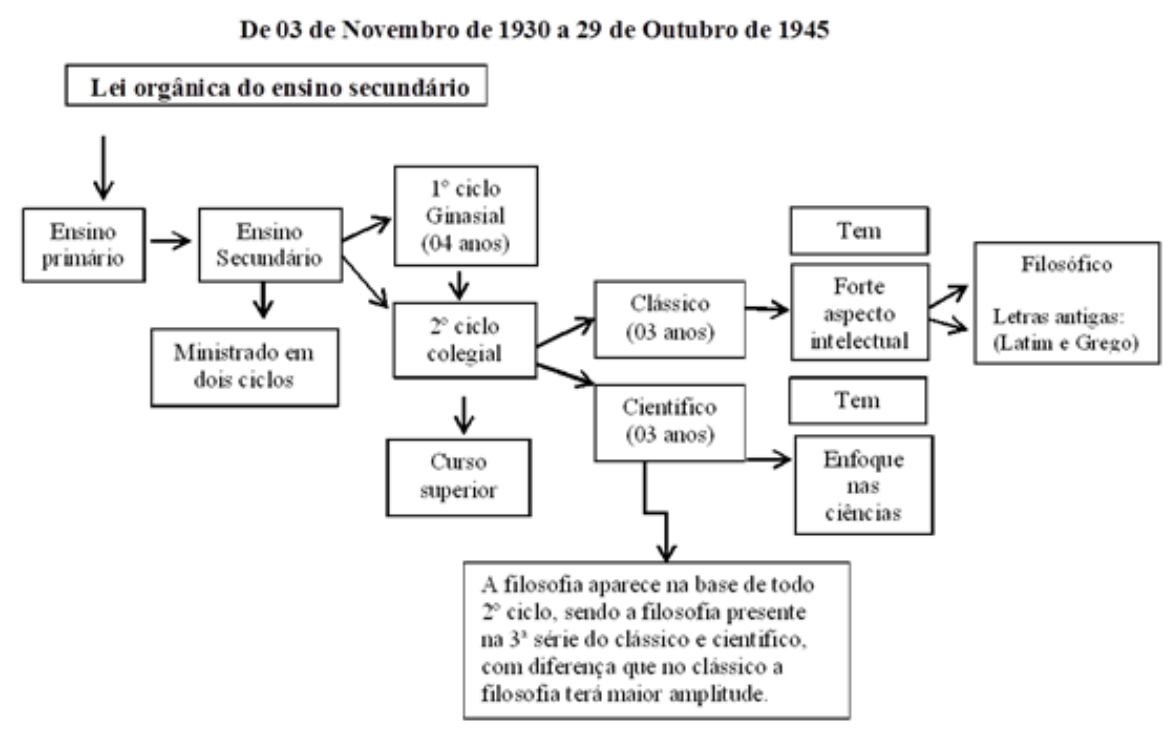

Fonte: Esquema elaborado pelos autores (2020).

É importante destacar que no segundo ciclo a disciplina Filosofia se fez presente nos dois cursos, tanto no científico, o qual tinha a formação voltada para o estudo das ciências, quanto no clássico, em que a filosofia estava presente de forma mais acentuada e tinha como finalidade fortalecer a formação intelectual.

Diante disso, observamos que em 1942 os governantes identificavam uma tímida relevância da disciplina Filosofia, independentemente do curso de segundo ciclo escolhido, ressaltando, assim, os percalços existentes para a relevância dela - em especial quando ligada à ciência.

A lei orgânica de 1946, referente ao ensino normal, tinha como finalidade a formação de docentes e administradores de escolas primárias e se dividia em dois ciclos: o $1^{\circ}$ ciclo não possuía filosofia em seu currículo e estava orientado para a formação de regentes do ensino primário, com duração de 4 anos; já o $2^{\circ}$ ciclo, com duração de 3 anos, objetivava a formação de professores primários e apresentava a Filosofia enquanto disciplina relevante para a formação docente. 
Figura 2 - Lei no 8.530 - 1946 (José Linhares)

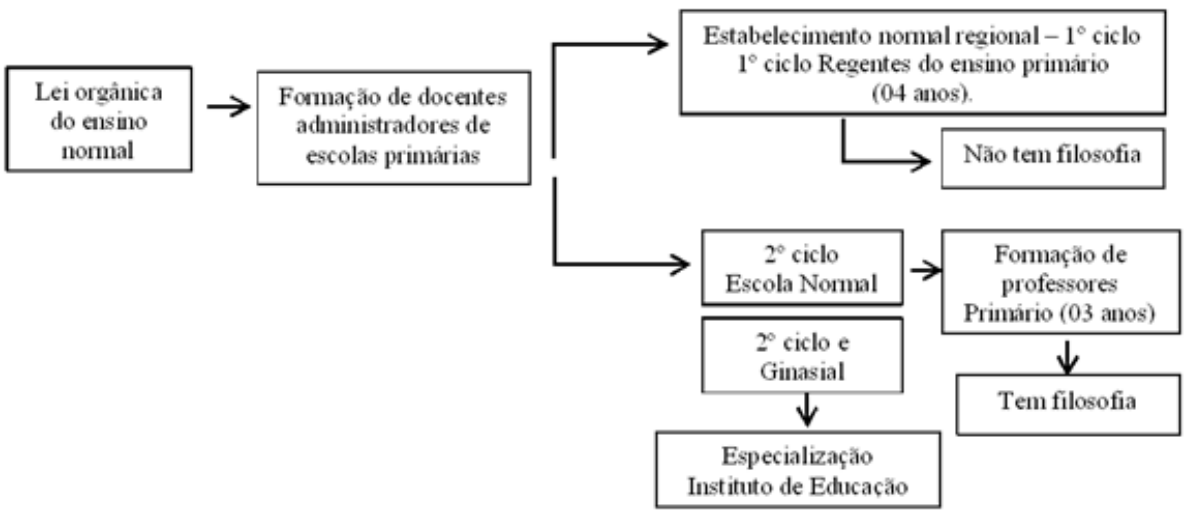

Fonte: Esquema elaborado pelos autores (2020).

Dito isso, é possível mencionar que a disciplina Filosofia se fez algo presente tanto no ensino secundário (o qual tinha como intuito o acesso ao nível superior) quanto no normal. Neste último, ainda que com seus problemas, a presença da disciplina parecia ter acanhada importância para a formação de professores de ciências.

Assim, "até o final dos anos de $1960^{8}$, a filosofia era inserida no modelo tradicional da escola brasileira secundária sem enfrentar grandes dificuldades para converter-se em saber escolar e definir seu estatuto disciplinar" (RODRIGO, 2009, p. 11). Mas essa estabilidade começou a ser comprometida no período da ditadura militar, via o golpe de Estado perpetrado em 31 de março e consumado em 01 de abril de 1964, tal como historicamente registrado nos manuais. Nesse período, a Filosofia foi destituída como disciplina obrigatória do currículo, sofrendo, assim, o ataque da ' 2 a onda' (opcionalização direta).

Essa reestruturação da disciplina da grade curricular da época tinha um objetivo, qual seja, dificultar que os civis, ao não terem contato com a filosofia, pudessem, pelas inúmeras razões óbvias, se tornar menos resistentes ao controle dos militares, concretizando um projeto de nação amplamente conhecido e divulgado nos livros de história. A filosofia era de fato uma ameaça à manutenção e ao progresso do governo militar. A ' 2 a onda' não ignorou que a contribuição da filosofia iria para além de formar cidadãos pensantes, pois ela contribuía para uma função fundamental no ensino de ciências: compreender uma imagem mais adequada da complexidade envolvida na construção e na prática do conhecimento científico. Noutros termos, até para os propósitos desenvolvimentistas do país que envolvessem a ciência, sendo esse um dos objetivos da época, a ausência da filosofia comprometia tais propósitos.

Avançando no tempo, como é sabido, o período ditatorial permaneceu por muito tempo no Brasil, 21 anos (1964 a 1985), e, durante todo esse período, a disciplina Filosofia não foi ensinada nas escolas. A ausência da disciplina durante todos esses anos, juntamente

\footnotetext{
${ }^{8}$ As leis de 1942 e 1946 foram utilizadas até o final dos anos de 1960. Em 1961, foi construída a primeira LDB - Lei de Diretrizes e Bases da Educação, que delimitava as disciplinas obrigatórias e deixava a inserção das optativas para ser escolhida pelos Estados. A filosofia era uma das disciplinas que eram consideradas optativas. Para mais sobre isso, ver: QUEIROZ, Maria Neuza Almeida; HOUSOME, Yassuko. As disciplinas científicas do ensino básico na legislação educacional brasileira nos anos de 1960 e 1970. Ens. Pesqui. Educ. Ciênc, Belo Horizonte, v. 20, e 9723, 2018.
} 
com os resquícios da reforma educacional tecnicista promovida pelo governo militar, no final dos anos 60 e início dos 70, deixaram para a educação do Brasil um problema enorme, pois o cenário comprometeu as disciplinas humanas e, com elas, as científicas, diante da compreensão de seus produtos e processos e da interdisciplinaridade.

Paralelamente a isso, a qualidade das disciplinas humanas e científicas, segundo Saviani (2008, p. 297), decresceu por causa da vinculação da educação pública aos interesses e às necessidades do mercado, quando sob viés da 'teoria do capital humano' e dos princípios de racionalidade, eficiência e produtividade, os quais, ao se pautarem numa concepção produtivista de educação, filosoficamente amparados na concepção positivista, se tornaram altamente influentes na compreensão de ciências nas escolas. Tal fato afetou os currículos nos cursos de ciências, promovendo empobrecimento e mercantilização dos alunos e dos conteúdos (SAVIANI, 2008).

Dessa forma, a modificação do sistema educacional da época proporcionou a retirada de disciplinas tão importantes como Filosofia dos currículos, fragilizando o sistema educacional brasileiro como um todo e, logo, até mesmo aquelas disciplinas em que se almejava ofertar maior qualificação geral, como as ciências naturais.

Além dos problemas daquele momento, trazidos pela ausência da filosofia, há ainda os problemas que depois de 35 anos do fim da ' 2 a onda' permanecem ressoando nas escolas, na sociedade e nas universidades. Por exemplo, pessoas formadas basicamente para o mercado de trabalho pouco atentas às reflexões filosóficas, sociais e educacionais que acompanham as ciências.

Essa formação puramente técnica, que deveríamos ter evitado, se iniciou no fim da década de 60, mas foi encorajada na Reforma Tecnicista de 1971, que englobou a Lei $\mathrm{n}^{0}$ 5.692, de 1971, e no Parecer $\mathrm{n}^{\mathrm{o}}$ 853/71, em ambos os casos retirando a disciplina Filosofia dos currículos para priorizar as disciplinas técnicas profissionalizantes, ao mesmo tempo que criaram um modelo de sociedade nos moldes militares ao adicionar as disciplinas Educação Moral e Cívica.

É interessante notar ainda a base teórica para a Reforma de 1971, a qual repousou sobre a chamada Pedagogia Redentora ${ }^{9}$, que, por sua vez, se concretiza na Pedagogia Liberal ${ }^{10}$ e suas subcorrentes, tal qual a tendência tecnicista. A Pedagogia Liberal tecnicista tem como finalidade, de acordo com Luckesi, "produzir indivíduos 'competentes' para o mercado de trabalho, transmitindo, eficientemente, informações precisas, objetivas e rápidas" (1994, p. 61). A pedagogia tecnicista

[...] foi introduzida mais efetivamente no final dos anos 60 com o objetivo de adequar o Sistema Educacional à orientação político-econômica do regime militar: inserir a escola nos modelos de racionalização capitalista. [...] Os marcos de implantação do Modelo tecnicista são as leis 5.540/68 e 5.692/71, que reorganizam o ensino superior e o ensino de $1^{\circ}$ e $2^{\circ}$ graus (LUCKESI, 1994, p. 61).

\footnotetext{
${ }^{9}$ De acordo com Luckesi (1994), a tendência redentora está totalmente voltada para a redenção da sociedade e propõe uma ação pedagógica otimista do ponto de vista político, que é considerado um otimismo ilusório pela tendência transformadora. A tendência redentora se traduz pelas pedagogias liberais, as quais se traduzem em: 1tendência tradicional, 2- renovada progressivista, 3- renovada não diretiva e 4- tecnicista.

10 Ainda segundo Luckesi (1994), o termo liberal não tem o sentido de "avançado", "democrático", "aberto", como costuma ser usado. A doutrina Liberal apareceu como justificação do sistema capitalista, que, ao defender a predominância da liberdade e dos interesses individuais da sociedade, estabeleceu uma forma de organização social baseada na propriedade privada dos meios de produção, também denominada sociedade de classes. A pedagogia liberal, portanto, é uma manifestação própria desse tipo de sociedade.
} 
As mudanças sofridas nos currículos com a retirada da disciplina Filosofia encontraram resistência nos movimentos que não aceitaram tais mudanças. Por exemplo, nos departamentos de filosofia, "os quais empreenderam um movimento de crítica de sua retirada e de defesa de seu retorno. Esse movimento teve êxito parcial quando, em meados dos anos 1980 foi aprovada a inclusão da disciplina filosofia como opcional, na parte diversificada do currículo" (GALLO, 2009, p. IX).

Dito isso, a escolha pela inserção da disciplina, a partir desse momento, ficava a cargo das Secretarias de Educação dos Municípios e dos diretores das escolas. Claro que essa inclusão não foi bem-sucedida, uma vez que os currículos ainda estavam sob forte influência da LDB (Lei de Diretrizes e Bases da Educação Nacional) de 1971. Na prática, 'a filosofia opcional' era o mesmo que pouco ou nada relevante, com a qual ou sem a qual o mundo permanecia tal e qual.

Passado o período ditatorial, os ecos dos debates em torno do descontentamento com a situação da ' 2 a onda' se fizeram presentes nos debates para a elaboração da nova LDB, a Lei $\mathrm{n}^{\circ}$ 9.394/96, lei brasileira que apresentou grande relevância no cenário educacional, embora, como apontou Saviani (2008), com os resquícios de 21 anos de ditadura refletidos na LDB de 96. Seja como for, um projeto aprovado na Câmara previa a obrigatoriedade das disciplinas Filosofia e Sociologia. Assim, os ventos pareciam soprar em favor da filosofia. Mas só pareciam. Chamemos esse período de ' 3 a onda' (opcionalização indireta).

A inserção da disciplina Filosofia encontrou novamente empecilhos, como descrito por Gallo (2009, p. IX): “O substitutivo Darci Ribeiro, porém, que seria aprovado como lei $\mathrm{n}^{\mathrm{o}}$ 9.394/96, em seu espírito flexibilizador e 'minimalista', optou por afirmar conhecimentos de filosofia e sociologia como obrigatórios, mas sem definir seu caráter disciplinar”. Noutros termos, a filosofia tinha ocupado lugar de relevância e obrigatoriedade, contudo sem se definir como, onde e quando.

Por volta dos anos 2000, a filosofia iria ganhar novo fôlego. Foi feita uma tentativa de inserção das disciplinas Filosofia e Sociologia no currículo, através de um projeto de lei (PLC $n^{\circ}$ 9/2000), de autoria do Deputado Federal Padre Roque Zimmermann, em 1997, que alterava o texto da LDB, aprovado na Câmara e pelo Senado em 18 de setembro de 2001. Porém, no mesmo ano, tivemos a ' 4 a onda' (obrigatoriedade transversal), no dia 08 de outubro. A proposta de Zimmermann, aprovada na Câmara e pelo Senado, foi vetada pelo Presidente da República Fernando Henrique Cardoso (FHC), doutor em Sociologia (sic), orientado a optar pela inserção das disciplinas como "temas transversais" (GALLO, 2009, p. X). Logo, a "4a onda' parece ter atacado a filosofia por um antigo argumento, a saber, o de que ela é tão necessária e grande que lhe reservar um lugar no currículo seria restringir seu alcance e diminuir sua grandeza. Obviamente, com isso áreas como ciências continuaram sendo vistas como autossuficientes, e estudantes brasileiros tinham grande desinteresse pelas ciências.

Em 2008, já no governo de Luiz Inácio Lula da Silva, as discussões sobre o assunto foram retomadas, e, de novo, parecia que os ventos sopravam as velas da filosofia, quando no dia "02 de julho de 2008 o presidente em exercício José Alencar, sancionou a lei que tornou obrigatório o ensino de filosofia e sociologia nas escolas públicas e privadas do ensino médio" (RODRIGO, 2009, p. 1) ${ }^{11}$. A disciplina em mote enfim se encontrava novamente inserida como disciplina obrigatória.

No entanto, novas dificuldades surgiram com o que chamaremos ' 5 ' onda' (obrigatoriedade disciplinar). A começar pela não compreensão dos estudantes sobre a

\footnotetext{
${ }^{11} \mathrm{O}$ autor se referiu ao mês de julho, porém assumimos que ele desejasse se referir à Lei ${ }^{\circ} 11.684$, de 2 de junho 2008.
} 
importância da disciplina Filosofia, uma sequela dos longos anos afastada das escolas, mas também de uma quantidade insuficiente de professores formados na área. Além disso, a insatisfação dos professores de outras áreas do conhecimento com o debate sobre a redistribuição da carga horária geral das disciplinas a fim de que Filosofia e Sociologia se enquadrassem na nova grade curricular não facilitou o retorno da filosofia.

Some-se a isso ainda a influência da tendência pedagógica liberal, que, desde o pósSegunda Guerra Mundial, encontrou abrigo nos cursos de ciências no Brasil e que, dado todo o cenário acima, não tinha como perceber os benefícios da Filosofia como disciplina. A relação entre filosofia e ciência continuou distante nas escolas e universidades brasileiras. Apesar de que, desde a década de 1990, a relação entre tais disciplinas era, dentro da literatura de educação em ciências, um tema consolidado.

Em suma, o lugar da filosofia, na educação geral e no ensino de ciências, ainda arca com as consequências do regime militar, e veremos os desdobramentos da ' 5 a onda' a partir da Lei no 13.415, de 2017, e da implementação da BNCC (Base Nacional Comum Curricular), que foi vigorada no ano de 2017.

\section{As implicações da BNCC e da Lei $n^{0} 13.415$ para o ensino de filosofia e para a educação científica}

Tomando como referência as aproximações, os distanciamentos e as reaproximações da disciplina Filosofia na educação brasileira e na educação científica a partir da Lei $\mathrm{n}^{\mathrm{o}}$ 13.415, de 2017, e da implementação da BNCC (Base Nacional Comum Curricular), vigorada no ano de 2017, é importante ressaltar a aparente falta de rumo que, por décadas, tem sido pauta planejada (ou caótica?) da educação brasileira. Como evidencia Krasilchik, "A cada novo governo ocorre um surto reformista que atinge principalmente os ensinos básico e médio" (2000, p. 85). Essas reformas atendem a interesses e acontecem tanto nacional quanto internacionalmente.

Por outro lado, o rumo da filosofia e da educação científica não é somente fruto dos governos, mas de quem constrói e mantém governos, de quem em realidade controla a política econômica do país, as forças neoliberais, na medida em que Calazans (1996) afirmou que as políticas públicas é que estão subjugadas aos interesses capitalistas, e dentre as quais, nosso texto mostra, a política de educação sobre o lugar da filosofia e de que tipo de cientista se quer formar. Essas 'ondas', longe de serem aleatórios fenômenos naturais, são, como bem sugeriu um dos avaliadores anônimos a quem agradecemos, fruto da condensação das lutas de classes na base da sociedade e não somente da história da falta de políticas de Estado, desvelando, assim, o conteúdo desse problema, um projeto de sociedade em disputa sob a pergunta "que sociedade mesmo se quer?".

Parte da resposta se vê no caso da filosofia, que, após um curto período de avanços, voltou a ser alvo de ataques com a Lei ${ }^{\circ} 13.415$, de 2017, a qual modificou a estrutura do Ensino Médio (composto pela BNCC e por itinerários formativos) (RAMOS; HEINSFELD, 2017). A organização do currículo passou a ser por áreas de conhecimento e, a Filosofia, de novo, enfrentou uma avalanche de ataque, a ' 6 ' onda' (obrigatoriedade por áreas de conhecimento), evidenciada no artigo a seguir:

\footnotetext{
Art. 36. O currículo do ensino médio será composto pela Base Nacional Comum Curricular e por itinerários formativos, que deverão ser organizados por meio da oferta de diferentes arranjos curriculares, conforme a relevância para o contexto local e a possibilidade dos sistemas de ensino, a saber:

I - linguagens e suas tecnologias;

II - matemática e suas tecnologias;
} 
III - ciências da natureza e suas tecnologias;

IV - ciências humanas e sociais aplicadas;

V - formação técnica e profissional (BRASIL, 2017, s/p).

Essa divisão por áreas de conhecimento na verdade fragmenta o ensino de filosofia e prejudica uma abordagem contextual do ensino de ciências relacionada com a filosofia, inserida em 2008 nas escolas de nível médio, públicas e particulares, agora reduzida a estudos e práticas: " $§ 2^{\circ}$ A Base Nacional Comum Curricular referente ao Ensino Médio incluirá obrigatoriamente estudos e práticas de educação física, arte, sociologia e filosofia" (BRASIL, 2017 , s/p). Isso sem mencionar a parte do art. 36, que diz conforme "a possibilidade dos sistemas de ensino", isto é, se não houver possibilidade, também não se tem a obrigação de criar condições para suprir a necessidade.

Essa redução da disciplina Filosofia a estudos e práticas prejudicou o seu ensino, desvalorizando seu estatuto disciplinar e também seu lugar em sala de aula e no sistema formativo para o aluno. Embora tenham sido contempladas na lei, há uma distinção em relação a algumas áreas (matemática e língua portuguesa), as quais empregam o termo "ensino" em contraponto à filosofia e demais áreas que empregam os termos "estudos" e "práticas", sem maiores orientações sobre sua aplicação (RAMOS; HEINSFELD, 2017). Mais do que isso, são ignorados toda a literatura e os avanços que, ao menos desde 1930, vêm indicando os mútuos benefícios da filosofia para a ciência.

Além da Lei $\mathrm{n}^{\circ}$ 13.415, de 2017, há outras modificações presentes na BNCC, um documento de caráter normativo que, apesar de citar a importância da contextualização para o ensino de ciências, não mostra aquilo que a literatura amplamente reconhece e que pode ser mais bem alcançado com discussões históricas e filosóficas:

\footnotetext{
$\mathrm{Na}$ Educação Básica, a área de Ciências da Natureza deve contribuir com a construção de uma base de conhecimentos contextualizada, que prepare os estudantes para fazer julgamentos, tomar iniciativas, elaborar argumentos e apresentar proposições alternativas, bem como fazer uso criterioso de diversas tecnologias. O desenvolvimento dessas práticas e a interação com as demais áreas do conhecimento favorecem discussões sobre as implicações éticas, socioculturais, políticas e econômicas de temas relacionados às Ciências da Natureza (BRASIL, 2017, p. 537).
}

Como podemos perceber, o documento não faz referência à Filosofia, mas menciona aspectos próprios dessa disciplina. Isso se estende por todo o documento ao não mostrar a importância das discussões filosóficas para a compreensão da natureza das ciências.

Assim, as novas diretrizes advindas da BNCC divergem totalmente dos aspectos mais contextuais da ciência e do ensino de ciências já aceitos pela literatura ao excluírem, por exemplo, oportunidades para abordar a natureza da ciência ou debater seu objetivo, o que, por sua vez, só ocorre a partir de uma real posição de relevância da filosofia no processo formativo do estudante.

Nesse sentido, o ensino de ciências precisa da filosofia para uma "fundamentada orientação, devendo ser ainda um referencial seguro para uma mais adequada construção das suas análises" (PRAIA; CACHAPUZ; GIL-PÉREZ, 2002, p. 128), uma vez que a filosofia é extremamente necessária para a compreensão da natureza das ciências.

Apesar do reconhecimento dessa importância da filosofia para o ensino de ciências na literatura, a situação não se reflete necessariamente nas escolas e na nossa legislação. As aulas de ciências (Biologia, Química e Física) estão distantes de fornecer aos estudantes um significado para sua aprendizagem e mesmo para o conteúdo em si, haja vista que leis, fatos e teorias científicas não se separam de debates filosóficos. Grandes cientistas, como Einstein, 
Newton e Darwin, entraram em debates desse tipo. Por que devemos ignorar tais fatos ao estudar suas teorias?

Ignorar esses elementos e separar a ciência da filosofia contribuem para, entre outras coisas, agravar o alto índice de analfabetismo científico. De acordo com o relatório do Centro Brasileiro de Análise e Planejamento (CEBRAP), pesquisas feitas nos Estados de São Paulo e Recife, com jovens do Ensino Médio, revelaram que eles não percebem utilidade no conteúdo das aulas de ciências naturais e humanas, sendo as disciplinas Língua Portuguesa e Matemática consideradas as mais úteis por, respectivamente, 78,8\% e 77,6\% dos alunos. Já Geografia, História, Biologia e Física, por sua vez, são consideradas descartáveis para 36\% (TORRES; TEIXEIRA; FRANÇA, 2013).

Como explicamos anteriormente, parte desse desinteresse dos estudantes pelas disciplinas científicas tem uma longa história, devendo-se a um ensino de ciências descontextualizado e que transmite uma imagem ingênua da atividade científica (GIL-PÉREZ et al., 2001), baseado numa ciência de conclusões em vez de processos, como disse Cobern (2000). Desse modo, muitas vezes os estudantes acabam por se distanciar da ciência por considerá-la impessoal e aborrecedora (FOURÉZ, 2003).

Por exemplo, o problema do método científico, majoritariamente ensinado nas aulas de ciências como um conjunto de regras e etapas exaustivas e infalíveis que conferem ao método um caráter indubitável e infalível ou quase infalível de verdades aproximadas, nem sequer é considerado um problema em sala de aula, ainda que nenhuma ciência moderna compartilhe dessa visão. Consequentemente, um dos requisitos básicos da alfabetização científica, a compreensão da natureza da ciência, fica extremamente prejudicada.

Mesmo com as evidências e recomendações da necessidade da filosofia, o cenário educacional brasileiro permanece instável por conta das reformas que culminaram no afastamento da filosofia. Infelizmente, até então, o lugar da filosofia como área e disciplina não se estabeleceu, principalmente quando olhamos de um ponto de vista temporal da história. Os poucos anos em que parecia desfrutar de algum avanço e indicar o reconhecimento na prática escolar dentro de outras disciplinas, como as ciências, arrefeceu e agora talvez se possa dizer que retrocedeu. Diante do exposto, fica claro que a filosofia não é o único alvo, embora seja o mais explícito, fato público e notório, diante de declarações públicas de autoridades contra cursos de filosofia no país. Talvez seja o caso de chamar esse movimento de sufocar a filosofia financeiramente de ' $7^{a}$ onda' (exclusão financeira da filosofia).

O efeito colateral do ataque à filosofia, embora aparentemente indesejado, é a própria ciência. Estudar ciências sem filosofia é abandonar as questões da natureza da ciência que com sorte surgirão aleatoriamente aqui ou ali, mas sem qualquer planejamento.

Por exemplo, o que um professor que não teve na formação docente ou no Ensino Médio uma disciplina de filosofia e história das ciências poderá responder a um aluno que lhe questione se 'a teoria da evolução é só uma teoria'? Saberá ele explicar a dimensão ontológica que constitui o debate sobre a noção de teoria, ou ele recorrerá ao argumento de que 'não é só uma teoria' porque está 'comprovada por fatos'? O que dirá então ao ser questionado sobre o que são fatos? Saberá entrar nesse debate ou mandará o aluno deixar de inconvenientes? E se perguntado por que acreditar nas ciências quando ela tem se mostrado decepcionante aos mais profundos problemas da humanidade?

É certo que essa problemática de 'ondas' de ataque à filosofia implica também prejuízo ao ensino de ciências. Infelizmente, as recentes modificações nas leis educacionais e 
a BNCC acabaram reforçando a situação de distanciamento, saindo a filosofia e a ciência prejudicadas após as 'ondas'. Fouréz afirma sobre essa relação:

Uma abordagem filosófica se opõe ao condicionamento dos cientistas 'técnicosperfeitos', mas incapazes de refletir sobre as implicações humanas de suas práticas [...] ao passo em que recusam absolutamente possuir conhecimentos apenas aproximativos de um domínio técnico (1995, p. 23).

Desse modo, o autor chama atenção tanto para a necessidade de uma reflexão filosófica na ciência quanto para uma compreensão do domínio científico por parte da filosofia para uma adequada compreensão e crítica.

Nesse sentido, essa mudança referente à filosofia que a reduz a estudos e práticas e que a exclui financeiramente representa um retrocesso no sistema educacional que terá seus efeitos visíveis no apagão de profissionais da área quando mais precisarmos, além de um apagão de uma formação integral e ética para os profissionais de ciências, ficando focados numa formação técnica e incapazes de refletir sobre sua prática, sua área, os processos e produtos, eliminando uma formação crítica e alfabetizada.

\section{Considerações finais}

Apesar de um número crescente de pesquisadores do ensino de ciências (re)afirmar a relevância da filosofia para a educação geral e para o ensino de ciências encontra diversos desafios na contemporaneidade, dentre eles o de manter seu estatuto disciplinar. As influências políticas e econômicas nos mostram que a filosofia consegue impactar a consolidação de uma ideologia dominante, apesar de se propor refletir sobre 'inutilidades'. Portanto, trouxemos ao debate as 'sete ondas' com a finalidade de demarcar os períodos de idas e vindas sobre o lugar da filosofia no Ensino Médio e como ela move outras áreas de formação não-humanas, a exemplo das científicas.

O currículo de ciências é afetado diretamente na medida em que a filosofia, a história e a filosofia das ciências são importantes para a formação de cientistas e o entendimento destes sobre a natureza da ciência. Ademais, não resta dúvida de que há uma relação entre as 'ondas' de afastamentos da filosofia do âmbito escolar e a crise no ensino de ciências, ocasionando o aumento do analfabetismo científico.

Em suma a filosofia enquanto disciplina está desde longa data sob ataque, mas cabenos perceber que isso se reflete também noutras disciplinas. Assim, a filosofia, ainda que não seja suficiente, é necessária para uma educação científica qualificada.

\section{Referências}

ADÚRIZ-BRAVO, Agustín; ARIZA, Yefrin. Importância de la Filosofia y de la História de la ciência en la Enseñanza y en el aprendizaje de las ciências. In: NASR, Z. M.; LEÓNSÁNCHEZ, R.; DE LEÓN, G. A. D. (Eds.). Enseñanza de la Ciência. México: UNAM, 2012. p. 79-82.

BRASIL. Decreto-lei no 4.244 - de 9 de abril de 1942. Lei orgânica do ensino secundário. Brasília, DF. Disponível em: https://repositorio.ufsc.br/. Acesso em: 16 maio 2018.

BRASIL. Ministério da Educação. Secretaria da Educação. Base Nacional Comum Curricular (Ensino Médio). Brasília, DF: Ministério da Educação, 2017. Dsiponível em: 
Revista de Educação, Ciência e Tecnologia
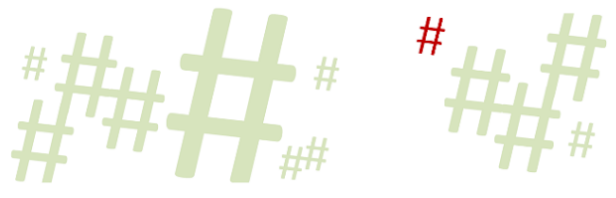

http://portal.mec.gov.br/conselho-nacional-de-educacao/base-nacional-comum-curricularbncc-etapa-ensino-medio. Acesso em: 15 jun. 2018.

BRASIL. Decreto-lei $n^{0} 6.141$, de 28 de dezembro de 1943. Lei orgânica do ensino comercial. Brasília, DF: Diário Oficial da União, 28 dez. 1943. Disponível em: https://www2.camara.leg.br/legin/fed/declei/1940-1949/decreto-lei-6141-28-dezembro-1943416183-publicacaooriginal-1-pe.html. Acesso em: 22 out. 2018.

BRASIL. Decreto-lei n. 8.530, de 2 de janeiro de 1946. Lei orgânica do ensino normal. Brasília, DF: Diário Oficial da União, 2 jan. 1946. Disponível em:

http://www.planalto.gov.br/ccivil_03/decreto-lei/1937-1946/del8530.htm. Acesso em: 16 maio 2018.

BRASIL. Lei de Diretrizes e Base de 1971 - Lei 5.692/71, de 11 de agosto de 1971.

Brasília, DF: Diário Oficial da União, 11 ago. 1971. Disponível

em:https://presrepublica.jusbrasil.com.br/legislacao/128525/lei-de-diretrizes-e-base-de-1971lei-5692-71. Acesso em: 16 maio 2018.

BRASIL. Parecer no 853/71, de 12 de novembro de 1971. Brasília, DF: Diário Oficial da União, 12 nov. 1971. Disponível em: file://C:/Users/Cliente/Downloads/parecer\%2085371.pdf. Acesso em: 16 maio 2018.

BRASIL. Lei 9394/1996, de 20 de dezembro de 1996. Lei de Diretrizes e Bases da Educação Nacional (LDB). Brasília, DF: Diário Oficial da União, 20 dez., 1996. Disponível em: http://www.planalto.gov.br/ccivil_03/leis/19394.htm. Acesso em: 15 maio 2018.

BRASIL. Lei $\mathbf{n}^{\mathbf{0}}$ 11.684, de 2 de junho de 2008. Altera o art. 36 da Lei no 9.394, de 20 de dezembro de 1996. Estabelece as diretrizes e bases da educação nacional, para incluir a Filosofia e a Sociologia como disciplinas obrigatórias nos currículos do ensino médio. 2 jun 2008. Disponível em: http://www.planalto.gov.br/ccivil_03/_ato2007-

2010/2008/lei/111684.htm\#: :text=L11684\&text=LEI\%20N\%C2\%BA\%2011.684\%2C\%20D E\%202,nos\%20curr\%C3\%ADculos\%20do\%20ensino\%20m\%C3\%A9dio. Acesso em: 15 fev. 2019.

BRASIL. Lei ${ }^{\circ}$ 13.415/2017, de 13 de fevereiro de 2017. Lei de Diretrizes e Bases da Educação Nacional. Altera as Leis $n^{\text {os }} 9.394$, de 20 de dezembro de 1996, que estabelece as diretrizes e bases da educação nacional, e 11.494, de 20 de junho 2007, que regulamenta o Fundo de Manutenção e Desenvolvimento da Educação Básica e de Valorização dos Profissionais da Educação, a Consolidação das Leis do Trabalho - CLT, aprovada pelo Decreto-Lei $\mathrm{n}^{\circ} 5.452$, de $1^{\circ}$ de maio de 1943, e o Decreto-Lei $\mathrm{n}^{\circ} 236$, de 28 de fevereiro de 1967; revoga a Lei n ${ }^{\circ} 11.161$, de 5 de agosto de 2005; e institui a Política de Fomento à Implementação de Escolas de Ensino Médio em Tempo Integral. 16 fev. 2017. Disponível em: http://www.planalto.gov.br/ccivil_03/_ato2015-2018/2017/lei/113415.htm. Acesso em: 17 fev. 2019.

CALAZANS, Maria Julieta. Planejamento da educação no Brasil: novas estratégias em busca de novas concepções. In: KUENZER, Acácia Zeneida; et al. Planejamento e educação no Brasil. São Paulo: Cortez, 1996.

COBERN, W. W. The Nature of Science and the Role of Knowledge and Bilief. Science and Educacion, v. 9, p. 219-246, 2000. 
ESCOLA NÃO É EMPRESA: Ataque do Neoliberalismo à Educação. Autor: Christian Laval. Editora: Boitempo Editorial. Setembro de 2019 (5:44 min.). Disponível em: https://www.youtube.com/watch?v=PbKVCOKdjWg. Acesso em: 08 out. 2020.

FEYERABEND, Paul. Against method. 3. ed. New York: Verso, 1993.

FIORI, Ernani. Prefácio. In: FREIRE, Paulo. Pedagogia do Oprimido. 17. ed. Rio de Janeiro: Paz e Terra, 1987.

FOURÉZ, Gerard. A construção das ciências: introdução à filosofia e à ética das ciências. Tradução: Luiz Paulo Rouanet. São Paulo: Editora da Universidade Estadual Paulista, 1995.

FOURÉZ, Gerard. Crise no Ensino de Ciências?. Investigações em Ensino de Ciências, Porto Alegre, v. 8, n. 2, p. 109-123, 2003. Disponível em:

https://www.if.ufrgs.br/cref/ojs/index.php/ienci/article/view/542/337 Acesso em: 20 de maio 2018.

FREIRE, Paulo. Educação como prática da liberdade. São Paulo: Paz e terra, 1980.

FREIRE, Paulo. Pedagogia do Oprimido. 17. ed. Rio de Janeiro: Paz e Terra, 1987.

FREIRE, Paulo. A importância do ato de ler: em três artigos que se completam. 46. ed. São Paulo: Cortez, 2005.

FREIRE JR., Olival. A relevância da filosofia e da história das ciências para a formação de professores de ciências. In: SILVA FILHO, W. J. Epistemologia e ensino de ciências. Salvador: Acádia, 2002. p. 13-30.

GALLO, Sílvio. Prefácio. In: RODRIGO, Lídia Maria. Filosofia em sala de aula: teoria e prática para o ensino médio. Campinas: Autores Associados, 2009. (Coleção formação de professores).

GIL-PÉREZ, Daniel; MONTORO, Isabel Fernández; ALÍS, Jaime Carrascosa; CACHAPUZ; António; PRAIA, João. Para uma imagem não deformada do trabalho científico. Ciência \& Educação, v. 7, n. 2, p. 125-153, 2001.

HURD, Paul de Hart. Scientific Literacy: New Minds for a Changing World. Science Education, v. 82, n. 3, p. 407-416, 1998. Disponível em: https://doi.org/10.1002/(SICI)1098237X(199806)82:3\%3C407::AID-SCE6\%3E3.0.CO;2-G. Acesso em: 20 maio 2018.

KRASILCHIK, Miriam. Reformas e realidade: o caso do ensino das ciências. Perspec. [online], v. 14, n. 1, p. 85-93, 2000. Disponível em: http://dx.doi.org/10.1590/S010288392000000100010. Acesso em: 20 maio 2018.

LUCKESI, Cipriano Carlos. Filosofia da Educação. São Paulo: Cortez, 1994.

MARCUSE, Herbert. A ideologia da sociedade industrial. Tradução de Giasone Rebuá. 3. ed. Rio de Janeiro: Zahar Editores, 1969.

MATTHEWS, Michael R. A Role for History and Philosophy in Science Teaching. Interchange, v. 20, n. 2, p. 3-15, 1989. Disponível em: https://doi.org/10.1007/BF01807043. Acesso em: Acesso em: 20 maio 2018. 
Revista de Educação, Ciência e Tecnologia

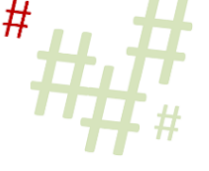

MATTHEWS, Michael R. História, Filosofia e Ensino de Ciências: A Tendência Atual de Reaproximação. Tradução de Claudia Mesquita de Andrade. Cad. Cat. Ens. Fís., v. 12, n. 3, p. 164-214, dez. 1995. Tradução de: History, philosophy, and science teaching: The present rapprochement. Science \& Education, v. 1, n. 1, p. 11-47, 1992.

MURI, Adriele Ferreira. Letramento científico no Brasil e no Japão a partir dos resultados do PISA. 2017. Tese (Doutorado em Educação) - Departamento de Educação do Centro de Teologia e Ciências Humanas, Pontifícia Universidade Católica, Rio de Janeiro, 2018.

PRAIA, João Felix; CACHAPUZ, António Francisco Carrelhas; GIL-PÉREZ, Daniel. Problema teoria e observação em Ciência: Para uma reorientação Epistemológica da Educação em Ciência. Ciência \& Educação, v. 8. n. 1, p. 127-145, 2002.

QUEIROZ, Maria Neuza Almeida; HOUSOME, Yassuko. As disciplinas científicas do ensino básico na legislação educacional brasileira nos anos de 1960 e 1970. Ens. pesqui. Educ. Ciênc., Belo Horizonte, v. 20, e9723, 2018.

RAMOS, Flávia Regina Oliveira; HEINSFELD, Bruna Damiana Sá Salón. Reforma do ensino médio de 2017 (Lei no 13.415/2017): um estímulo à visão utilitarista do conhecimento. In: IV Congresso Nacional de Educação. 2017. Disponível em: https://www.researchgate.net/publication/320265714. Acesso em: 30 ago. 2018.

RODRIGO, Lídia Maria. Filosofia em sala de aula: teoria e prática para o ensino médio. Campinas: Autores Associados, 2009. (Coleção formação de professores).

SASSERON, Lúcia Helena; CARVALHO, Ana Maria Pessoa. Alfabetização científica: uma revisão bibliográfica. Investigações em Ensino de Ciências, v. 16, n. 1, p. 59-77, 2011.

SAVIANI, Demerval. O legado educacional do regime militar. Cad. Cedes, v. 28, n. 76, p. 291-312, 2008. Disponível em: http://dx.doi.org/10.1590/S0101-32622008000300002. Acesso em: 20 maio 2018.

SCHULTZ, Theodore. Investment in Human Capital. The American Economic Review, v. 51, n. 1, p. 1-17, mar., 1961.

TORRES, Haroldo da Gama; TEIXEIRA, Jacqueline Moraes; FRANÇA, Danilo. O que pensam os jovens de baixa renda sobre a escola. Educação \& Pesquisas Educacionais, São Paulo: Fundação Victor Civita, p. 167-204, 2013. Disponível em:

https://www.researchgate.net/publication/273955346_O_que_os_jovens_de_baixa_renda_pen sam_sobre_a_escola. Acesso em: 22 maio 2018.

Recebido em julho de 2020.

Aprovado em novembro de 2020. 